\title{
GRAFIS LINGKUNGAN WISATA AIR PANAS SEMURUP
}

\author{
Rino Yuda \\ Desain Komunikasi Visual, Jurusan Seni Rupa dan Desain, Institut Seni Budaya Indonesia Aceh, \\ Jantho, Aceh \\ E-mail: rinoyuda@isbiaceh.ac.id, HP: +6281266643727
}

\begin{abstract}
ABSTRACK
In Semurup Hot spring tourism is located in Kerinci district. In the days of occupation dutch indies, Semurup Hot springs totally used by the dutch indies as a bathhouse army troops. Bathhouse hot water in this tourism has many benefits that efficacious cure diseases. In Semurup Hot spring tourism itself is have two spots hot springs separate, including hot springs 1 and 2 with various facilities and has plenty of hot springs. In Semurup Hot spring tourism it has no means of public information inadequate. In this case is necessary information systems and system a good sign of graphic environment, to simplify tourists in identifying facilities about what can and cannot approached by tourists, as hot springs at the hot water temperatures $90^{\circ} \mathrm{C}$ more. The presence of a media application of Environmental Graphics, overall information about places, buildings, facilities and so forth can be well ordered.
\end{abstract}

Keywords: Semurup Hot Spring Tourism, Environmental Graphics.

\begin{abstract}
ABSTRAK
Di Wisata Sumber Air Panas Semurup merupakan objek wisata yang terletak di Kabupaten Kerinci. Pada zaman penjajahan Hindia Belanda, Sumber Air Panas Semurup ini sempat dimanfaatkan oleh Pemerintah Hindia Belanda sebagai tempat pemandian prajurit militer. Pemandian Air Panas di wisata ini memiliki banyak manfaat yang berkhasiat menyembuhkan penyakit. Di kawasan wisata Sumber Air Panas Semurup ini sendiri memiliki dua tempat sumber air panas yang terpisah, diantaranya Sumber Air Panas 1 dan 2 dengan berbagai fasilitas dan memiliki banyak sumber mata air panas. Di kawasan Wisata Air Panas Semurup ini tidak memiliki sarana informasi publik yang tidak memadai. Dalam hal ini sangat diperlukan sistem informasi dan sistem tanda yang baik berupa Grafis Lingkungan, agar mempermudah wisatawan dalam mengidentifikasi fasilitas tentang apa yang boleh dan tidak boleh didekati oleh wisatawan, seperti sumber air panas pada kolam air panas dengan suhu $90^{\circ} \mathrm{C}$ lebih. Dengan adanya suatu penerapan media Grafis Lingkungan, keseluruhan informasi mengenai tempat, bangunan, fasilitas dan sebagainya dapat tertata dengan baik.
\end{abstract}

Kata kunci : Wisata Air Panas Semurup, Grafis Lingkungan. 


\section{PENDAHULUAN}

Kabupaten Kerinci dikenal sebagai Kabupaten yang memiliki panorama yang terindah di Provinsi Jambi. Sakti Alam Kerinci merupakan sebutan lain dari Kabupaten Kerinci. Kerinci dikenal dengan julukan "Sepenggal Tanah Surga", sebutan ini merefleksikan betapa wilayah Kerinci memiliki panorama yang sangat memukau.

Salah satu objek wisata yang menjadi wisata andalan daerah Kabupaten Kerinci, yaitu objek Wisata Air Panas Semurup. Wisata Air Panas Semurup ini berada di Desa Air Panas Baru, Kecamatan Air Hangat, Kabupaten Kerinci, Provinsi Jambi. Kegiatan yang dilakukan oleh wisatawan yang berkunjung ke objek ini, yakni merebus telur dan pisang. Di samping itu, terdapat fasilitas khusus kolam renang air panas, tempat perendaman kaki air panas, dan kamar mandi air panas yang berkhasiat untuk penyembuhan penyakit kulit (health tourism) dan sebagainya.

Ditinjau dari sektor pelayanan dikawasan wisata secara umum, selain fasilitas yang lengkap, akan tetapi juga dibutuhkan suatu sistem penanda untuk mempermudah wisatawan menemukan tempat objek wisata, maupun mengindentifikasi fasilitas yang ada dikawasan wisata itu sendiri. Selain itu dibutuhkan juga suatu landmark wisata yang berfungsi sebagai citra dan identitas. Dalam hal ini Wisata Air Panas Semurup belum memiliki landmark dan belum pernah dirancang sebelumnya.

Di kawasan Wisata Air Panas Semurup ini sendiri memiliki dua tempat sumber air panas yang terpisah, diantaranya Air Panas 1 dan Air Panas 2, berjarak dari satu tempat ke tempat lain \pm 200 Meter. Hal ini dapat membingungkan pengunjung melalui pintu masuk yang bebeda dengan tanpa adanya suatu petunjuk seperti Map Sign yang berfungsi sebagai identifikasi jalan, tempat bangunan, dan lain sebagainya. Selain itu juga terdapat tanda larangan pada bagian-bagian di sumber air panas yang tidak diperbolehkan memasuki area tersebut, karena berdampak bagi keselamatan pengunjung. Dalam hal ini terdapat beberapa sistem tanda yang ada dikawasan wisata Air Panas Semurup yang sudah layak pakai dan usang. Sangat disayangkan kawasan Air Panas Semurup kurang diimbangi dengan penggunakan sistem tanda yang baik dan mudah diidentifikasi pengunjung. Sistem tanda sangat penting dibutuhkan pengunjung untuk alat bantu dalam berinteraksi dengan ruang. Dengan gambaran ini, maka Wisata Air Panas Semurup membutuhkan suatu sistem tanda dalam cangkupan grafis lingkungan untuk memudahkan pengunjung berinteraksi dengan lingkungan.

\section{STUDI LITERATUR}

Hendra Afriwan (2010) dalam Wisata heritage Kota gede ini dulu merupakan peninggalan dari kerajaan Mataram yang saat ini dijadikan sebagai tempat wisata. Konsep yang diaangkat dalam rancangan ini adalah tradisional dengan kesan klasik dan artistik. Pada lamdmark yang dirancang diambil dari bentuk gapura yang menjadi ciri khas dari wisata ini. Secara prinsip menggunakan teori gestal. Dalam rancangan diatas memliliki landmark yang sudah ditentukan seperti Wisata Heritage Kota Gede menjadikan Gapura sebagai Dari aspek pemilihan konsep warna juga berbeda, Wisata Heritage Kota Gede warna klassik dan artistik yang 
dianggkat dari unsur budaya. Selain itu bentuk sign yang dirancang menggunakan bahan seperti, seng plat, besi untuk penyangga, tonggak besi dan lampu hias. Terdapat penambahan motif, kesan yang ingin dimunculkan adalah tradisional dan klasik.

Sementara itu, Yon Ade Lose Hermanto (2011) dalam tulisannya Grafis Lingkungan Jatim Park 2 ini menggunakan teknik gestalt. Gestalt merupakan sebuah teori psikologi yang mengatakan bahwa seseorang akan mempersepsikan apa yang terlihat dari lingkungannya sebagai satu kesatuan utuh. Teori ini dapat menjelaskan kecenderungan persepsi yang terbentuk di benak seseorang. Logo Jatimpark menggunakan 2 pendekatan gestalt. Similarity digunakan pada tulisan 'JAWATIMUR' yang menggunakan warna sama yang akan dilihat sebagai satu kelompok tersendiri. Sedangkan Figure Ground digunakan pada ikon-ikon yang menggambarkan 4 hewan: gorilla, pinguin, burung hantu, dan bunglon. Ikon-ikon bergambar hewan itu digambarkan simpel karena kesimpelan tersebut membantu mempercepat pengidentifikasian isi gambar tersebut. Ikon yang dipakai menggunaka border (batas pinggir). Hal ini dimaksudkan ikon-ikon tersebut dapat berdiri sendiri dan membantu memisah dengan ikon lain, karena batas pinggir dapat membantu memisahkan elemen dari gambar atau background.

Nur Abi Abdiansyah (2011) Grafis Lingkungan Kota Tua Makasar terinspirasi dari tampak depan Benteng Rotterdam. Benteng ini dipilih sebagai ikon Kota Tua Makassar karena letaknya yang mencolok dan monumental ditengah kota. Banteng ini berada di jalur utama dan bersama pantai losari menjadi ikon Kota Tua Makassar. Kesan klasik dan tua ini dibangun dari visual dinding banteng yang sengaja ditampilkan tidak beraturan, diimbangi dengan kesan modern melalui Logotype yang jelas dan tegas. Konsep asimetris dan perspektif pada logo ini memberikan kesan kedalaman dan nostalgia kota Makassar dimasa silam. Pemilihan warna coklat dan kuning gading dimaksudkan untuk memperkuat impresi kedewasaan logo ini. Warna coklat menunjukkan kewibawaan dan kemampanan, kesan alami dan membumi, sedangkan kuning gading memberikan kesan anggun dan kesuksesan.

\section{METODE}

Ruang lingkup merupakan pengelompokan masyarakat atau segmentasi berdasar kriteria tertentu. Segmentasi ini merupakan bentuk keseluruhan dari target segmen. Segmen yang ditujukan disini adalah wisatawan yang akan datang, menuju, atau sudah berada di Kabupaten Kerinci. Dari segmentasi inilah nantinya muncul target segmen, segmentasi didasarkan dari demografis, geografis, dan psikografis. Pada kajian segmentasi kali ini, target segmen berfungsi untuk mempelajari audiens pengunjung Kawasan Wisata Air Panas Semurup dari berbagai aspek, sehingga nantinya, hasil yang dicapai dapat menyentuh kebutuhan audiens.

Pengumpulan data terdiri dari wawancara, observasi, studi pustaka. Wawancara dilakukan langsung dari nara sumber yaitu Kepala Dinas Pariwisata dan Kebudayaan Kabupaten Kerinci dan Kepala UPTD Air Panas Semurup. Observasi yaitu penelitian atau kunjungan di lapangan 
secara langsung berguna sebagai penentuan segmentasi dan target audiens. Selain itu bertujuan untuk melihat secara langsung kekurangan dari segi sign system yang ada dikawasan Wisata Air Panas Semurup. Studi Pustaka dilakukan buku Rencana Induk Pengembangan Wisata Air Panas Semurup, artikel/ media yang dapat digunakan sebagai sumber data yang mendasari dalam proses rancangan. Analisis SWOT yaitu untuk melihat kekuatan, kelemahan, peluang, ancaman tehadap karya Grafis Lingkungan yang dirancaang untuk kebutuhan Wisata Air Panas Semurup.

\section{HASIL DAN PEMBAHASAN}

Logo pada zaman sekarang dan di masa depan terus mengalami perubahan dan berkembang. Akan ada banyak istilah-istilah baru yang bermunculan, tidak ada istilah yang paling sempurna untuk mewakili anatomi dari jutaan logo yang yang ada saat ini. Istilah yang digunakan "Taxono my of Trademarks" karya Per Mollerup: Picture Mark dan Letter Mark, kiranya cukup memadai untuk menyebut elemen gambar dan elemen tulisan dalam sebuah logo. (Surianto Rustan, 2013: 20).

Pembuatan Landmark, perlu adanya identifikasi kawasan wisata sebelum melakukan proses sketsa. Hal ini merupakan bagian dari brainstorming untuk menemukan karakter yang berciri khas untuk dijadikan suatu landmark. Mata air panas atau sumber air panas dijadikan sebagai ide rancangan merupakan energi yang berasal dari perut bumi. Ekologi energi panas merupakan sumber daya tak ada habisnya. Proses terbentuknya sumber air panas disebabkan oleh curah hujan yang diserap oleh tanah kedalam sumber terpanas bumi, kemudian muncul lagi sebagai sebagai uap atau air panas.

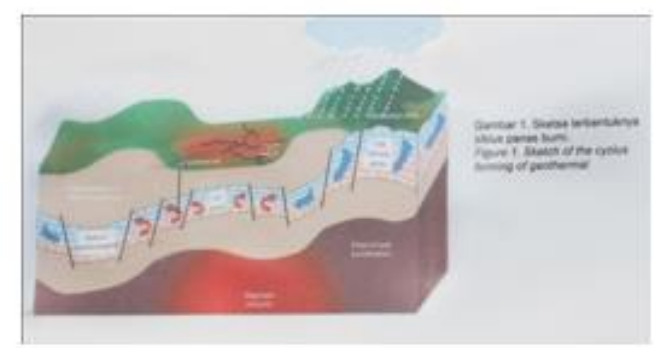

Gambar 1 : Proses terbentuknya sumber air panas

Sumber : www.geoparkmeranginjambi.com

Sumber air panas di Objek Wisata Air Panas Semurup memiliki daya tarik yang kuat dan memiliki banyak manfaat, selain itu keindahan kolam sumber air panas ini memiliki warna biru kehijauan yang indah dan mengeluarkan uap panas. Gagasan Ini kemudian dituangkan kedalam bentuk sketsa untuk kebutuhan landmark atau logo sebagai identitas Objek Wisata.

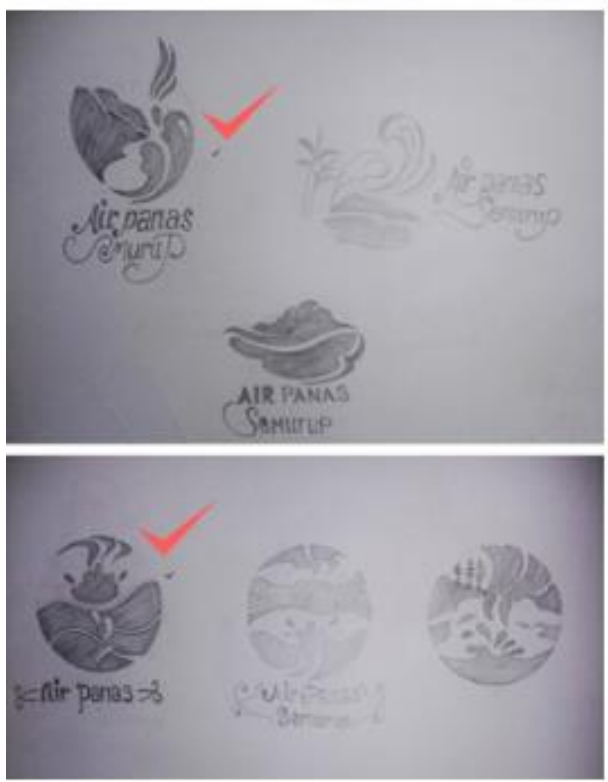

Gambar 2 : Proses sketsa

Sumber : Dokumen pribadi penulis. 2016

Setelah didapat ikon terpilih, kemudian dikembangkan kembali dalam bentuk digital untuk dipilih 
menjadi Final Ikon. Dari alternatif sebelumnya terdapat beberapa pengembangan dan gabungan ikon untuk dikembangkan lebih lanjut.
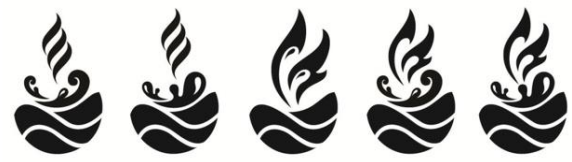

Gambar 3 : Proses pembuatan landmark digital

Sumber : Dokumen pribadi penulis. 2016

Selanjutnya pembuatan tipografi melalui sketsa maupun digital. Tipografi ini berfungsi sebagai pendukung dalam landmark , pendukung dimaksud ialah sebagai bagian identitas landmark objek wisata akan tetapi tetap menjadi satu kesatuan antara ikon dengan tipografi.
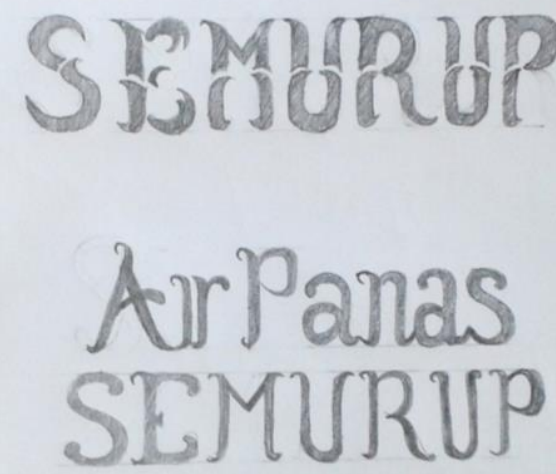

Gambar 4 : Pembuatan Tipografi

Sumber : Dokumen pribadi penulis. 2016

Dalam studi warna landmark wisata Air Panas Semurup, kesan utama yang ingin dicapai adalah alami, panas, elegan dan mampu memberikan impresi yang kuat terhadap citra wisata Air Panas Semurup, serta memiliki faktor keterbacaan yang jelas bila diterapkan ke berbagai media. Warna memiliki hubungan yang erat dengan identitas visual. Warna juga impresi dari citra, makna dan tanda. Dalam perancangan landmark wisata Air panas Semurup menggunakan tiga komponen warna yaitu, merah, biru, dan orange.

Dalam pemakaian warna yang kurang tepat maka dapat merusak citra, mengurangi nilai keterbacaan, dan bahkan dapat menghilangkan gairah baca. Jika penggunaan warna yang tepat maka warna dapat membantu menciptakan mood dan membuat teks lebih berbicara. (Rakhmat Supriyono, 2010 : 70).

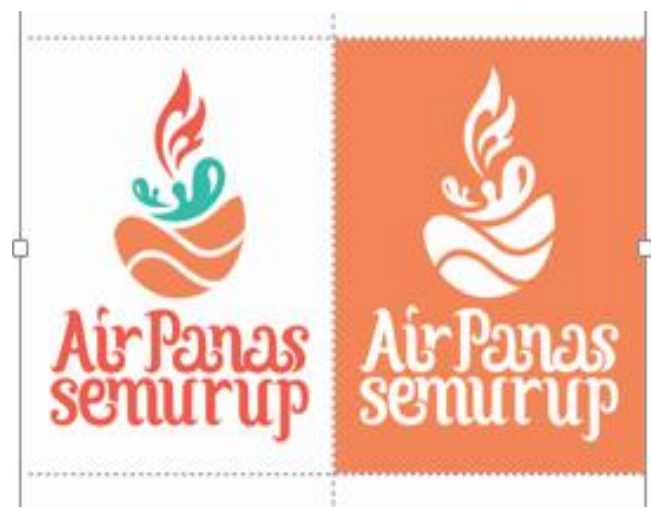

Gambar 5 : Warna Landmark

Sumber : Dokumen pribadi penulis. 2016

Selanjutnya tahapan penyusunan makna landmark agar identitas objek wisata ini menjadi kuat dan mewakili keseluruhan citra objek wisata ini perlu adanya makna dari landmark dari objek wisata tersebut. 


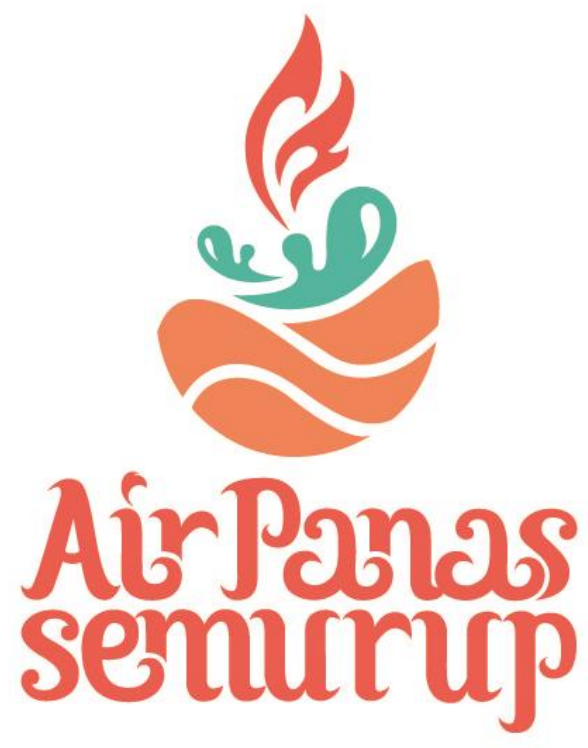

Gambar 6: Final Landmark Sumber : Dokumen pribadi penulis. 2016

Tiga elemen ikon tanah, air, dan panas mempresentasikan proses terbentuknya sumber air panas. Pola bentuk tetesan air yang jatuh dari atas melambangkan tetesan air hujan. Tanah sebagai perantara penyerap air kedalam sumber terpanas bumi dan mengeluarkannya kembali sebagai sumber mata air panas. Bentuk susunan tanah sengaja memiliki ruang sempit yang menandakan lapisanlapisan tanah dan sebagai jalur mata air yang keluar dari dasar bumi.

Pemilihan tiga warna merah, biru dan orange memiliki makna yang berbeda. Warna merah dimaksudkan untuk memperkuat impresi atau tekanan yang menandakan air panas. Wisata air panas semurup ini adalah wisata alam, warna biru adalah warna yang tepat dipakai untuk meberikan kesan alami. Warna biru diadaptasi dari warna air pada kolam air panas. Air panas ini dihasilkan dari alam masih terjaga kealamiannya, tanpa ada pengolahan sebelumnya dan dapat dirasakan manfaatnya secara langsung.
Warna orange diadaptasi dari warna tanah dan batu karang yang ada dikawasan wisata Air panas semurup. Warna orange memperkuat kesan hangat pada sumber air panas. Warna orange juga melambangkan optimisme yaitu dengan adanya wisata air panas ini dapat memberikan pengharapan dan manfaat yang baik, sesuai dengan tujuan wisata air panas semurup ini untuk memberikan kecerian, kehangatan, dan manfaat kepada konsumennya.

Setelah pembuatan identitas lanjut pada pembuatan Sign System dimana Sign System ini berfungsi sebagai penanda, pengarah untuk mempermudah wisatawan dalam menemukan fasilitas yang ada dikawasan objek wisata.

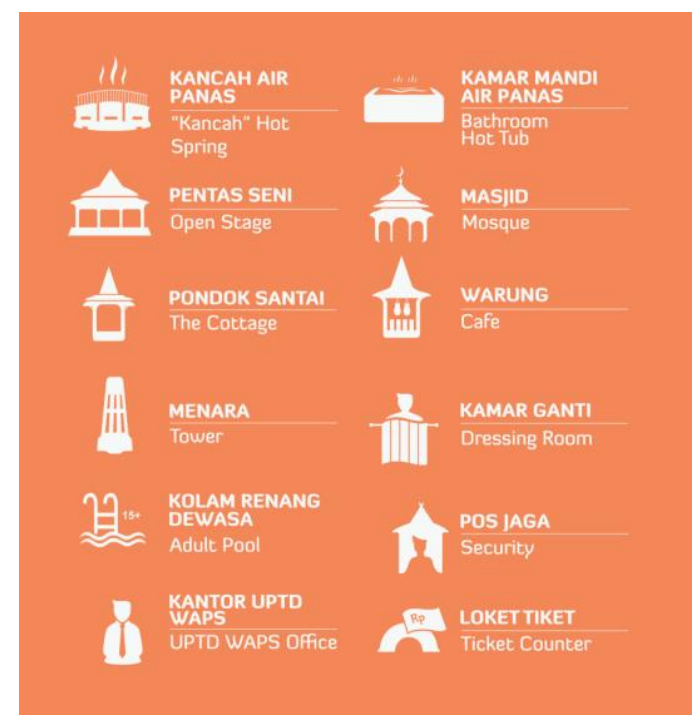

Gambar 7: Sign System

Sumber : Dokumen pribadi penulis. 2016 


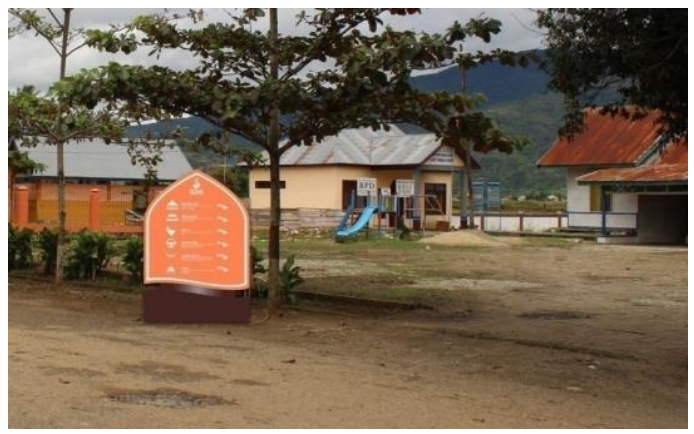

Gambar 8: Contoh penerapan Sign System Sumber : Dokumen pribadi penulis. 2016

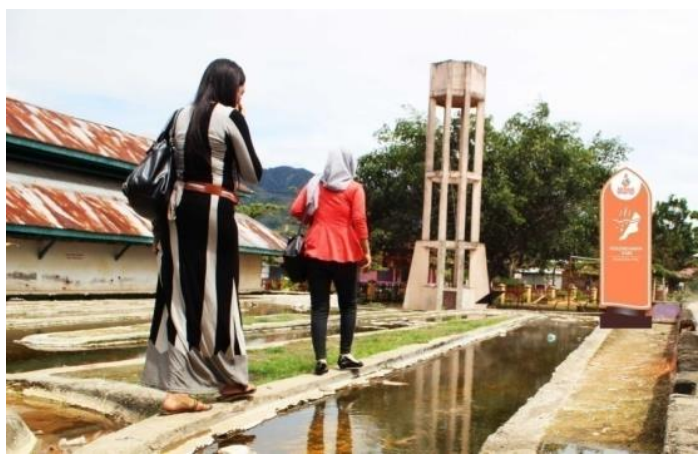

Gambar 9: Contoh penerapan Sign System Sumber : Dokumen pribadi penulis. 2016

\section{KESIMPULAN}

Grafis lingkungan adalah suatu ilmu yang komplit, dimana dalam proses penerapannya grafis lingkungan didukung dengan banyak ilmu dan teori seperti logo, piktogram, arsiterktur, komunikasi, semiotika, interior, desain industri, dan semua yang bersangkutan dengan aspek visual wayfinding. Grafis Lingkungan melibatkan orkestrasi tipografi, warna, citra, bentuk, teknologi dan, terutama, konten untuk menciptakan lingkungan yang berkomunikasi. Grafis lingkungan tidak hanya sekedar merancang logo, piktogram ataupun sign system, akan tetapi merancang suatu grafis lingkungan adalah suatu pengalaman merancang sistem tanda yang tersistem secara baik dan benar. Dalam hal ini adalah untuk kepentingan informasi publik yang berinteraksi dengan lingkungan.

\section{DAFTAR PUSTAKA}

Rustan, Surianto. 2008. Mendesain Logo. Jakarta: PT Gramadia Pustaka.

Supriyono, Rahkmat. 2010. Desain Komunikasi Visual Teori dan Aplikasi. Yogyakarta: Andi.

Abdiansyah, Abi Nur. 2011. Perancangan Grafis Lingkungan Kota Tua Makassar.

Yogyakarta: ISI Yogyakarta.

Afriwan, Hendra. 2010. Perancangan Grafis Lingkungan Wisata Heritage Kota Gede. Yogyakarta: ISI Yogyakarta.

Hermanto, Yon Ade Lose. 2011. Perancangan Grafis Lingkungan Jawatimur Park2. Yogyakarta: ISI Yogyakarta.

\section{WEBTOGRAFI}

www.geoparkmeranginjambi.com 